\title{
OCCUPATIONAL ALLERGIC AND IRRITANT CONTACT DERMATITIS IN WORKERS EXPOSED TO POLYURETHANE FOAM
}

\author{
MARTA KIEĆ-ŚWIERCZYŃSKA, DOMINIKA ŚWIERCZYŃSKA-MACHURA, \\ DOROTA CHOMICZEWSKA-SKÓRA, EWA NOWAKOWSKA-ŚWIRTA, and BEATA KRĘCISZ
}

\author{
Nofer Institute of Occupational Medicine, Łódź, Poland \\ Department of Allergology and Environmental Health
}

\begin{abstract}
Objectives: To evaluate sensitization to chemicals present in work environment after an outbreak of contact dermatitis in workers of vehicle equipment factory, exposed to polyurethane foam, based on 4,4'-diphenylmethane diisocyanate (MDI). Material and Methods: From among 300 employees, 21 individuals reporting work-related skin and/or respiratory tract symptoms underwent clinical examination, patch testing, skin prick tests, spirometry and MDI sIgE measurement in serum. Patch tests included isocyanates series, selected rubber additives, metals, fragrances, preservatives, and an antiadhesive agent. Results: Clinical examination revealed current eczema in the area of hands and/or forearms in 10 workers. Positive patch test reactions were found in 10 individuals, the most frequent to diaminodiphenylmethane and 4-phenylenediamine (7 persons). Reactions to an antiadhesive agent were assessed as irritant (5 workers). Except for sensitization to common aeroallergens, no significant abnormalities were found in the remaining tests. Occupational allergic contact dermatitis was diagnosed in 7 workers, irritant contact dermatitis in 10 and coexisiting allergic and irritant contact dermatitis in 3 workers. Conclusions: In workers manufacturing products from polyurethane foam, attention should be paid to the risk of developing contact dermatitis. Skin problems in our study group were attributable probably to insufficient protection of the skin.
\end{abstract}

\section{Key words:}

Polyurethanes, Isocyanates, 4,4'-diphenylmethane diisocyanate (MDI), Diaminodiphenylmethane (MDA),

Occupational contact dermatitis

\section{INTRODUCTION}

Polyurethanes (PU) are resins formed by a condensation or adduction reaction between isocyanates and polyol type compounds [1]. Isocyanates, the basic materials for the synthesis of PU, are aromatic, aliphatic or cycloaliphatic chemicals with a low molecular weight and a highly reactive $-\mathrm{N}=\mathrm{C}=\mathrm{O}$ group [2]. Polyols, multifunctional alcohols, are polyesters or polyethers with multiple hydroxyl groups [1,3]. Among additional substances, essential in manufacturing of PU products, there are also catalysts such as diaminodiphenylmethane (MDA), triethylenediamine, triethylamine and cobalt, nickel, copper and lead salts [1].

Polyurethanes products include flexible and rigid foams, fibers, coatings (paints and varnishes), adhesives and elastomers. Many of them, especially rigid foams, are

\footnotetext{
This study was conducted as part of the realization of the Nofer Institute of Occupational Medicine project entitled "Assessment of health effects of inhalative exposure to diisocyanates of polyurethane foam factory workers", financed with the resources granted by the Polish Ministry of Science and Higher Education. Head of the project: Dominika Świerczyńska-Machura, MD, PhD.

Received: November 26, 2013. Accepted: January 22, 2014.

Corresponding author: D. Chomiczewska-Skóra, Nofer Institute of Occupational Medicine, Department of Allergology and Environmental Health, św. Teresy 8, 91-348 Łódź, Poland (e-mail: chomicz@imp.lodz.pl).
} 
based on two aromatic isocyanates: toluene diisocyanate (TDI) and 4,4'-diphenylmethane diisocyanate (MDI). Aliphatic isocyanates, such as isophorone diisocyante (IPDI) and 1,6-hexamethylene diisocyanate (HDI) are used in products requiring light and weather resistance [4]. PU products have a variety of industrial applications, e.g. in the automobile industry. PU foams can be found in seats, armrests and headrests of most cars and also within the bodies of vehicles where their insulation properties provide protection against the heat and noise of the engine [5].

Occupational exposure to PU foam, during its production or application in manufacturing of various products, may result in health problems affecting airway and skin. The health risk is a consequence of toxic, irritant and allergic properties of isocyanates, less frequently of irritant or allergic effects of other compounds, for instance catalysts and PU additives [1]. Isocyanates are considered the most common cause of occupational asthma in industrialized countries, where its prevalence among exposed workers ranges from 1 to even $25 \%$ [6,7]. These chemicals were also reported as causal factors of other respiratory disorders as non-obstructive bronchitis, rhinitis, chronic obstructive airway disease and extrinsic allergic alveolitis (hypersensitivity pneumonitis) [7]. Moreover, cases of urticaria due to MDI[8-10] were demonstrated.

Exposure to diisocyanates, polyisocyanates and PU additives may also result in allergic and irritant contact dermatitis (ACD, ICD) but they are considered a non-frequent phenomenon [1,11]. However, quite a few authors reported well-documented cases of ACD in a number of different workplace and non-occupational settings. Isocyanates causing ACD included MDI [2,12-15], TDI [2], HDI [2,16] and dicyclohexylmethane-4,4'-diisocyanate (DMDI, synonymous with hydrogenated methylene-4,4'diphenyldiisocyanate - HMDI) [17-21]. ACD due to MDI was seen more frequently than that related to other isocyanates, which may be a consequence of the fact that MDI represents more than a half of the worldwide isocyanate production [4].

The aim of this paper was to evaluate sensitization to chemicals present in work environment after an outbreak of contact dermatitis in workers of vehicle equipment factory, exposed to polyurethane semi-rigid foam based on MDI.

\section{MATERIAL AND METHODS}

The investigation was performed in vehicle equipment factory, where acoustic and thermal insulations, shields, covers, carpets, flooring, mats and other accessories were manufactured from various materials. Due to numerous cases of skin problems (and less often respiratory problems) in workers, the management of the factory addressed a request to the Nofer Institute of Occupational Medicine (Łódź, Poland) for examination of employees and establishing the causal factors of the disorders. From among 300 workers, 21 persons who reported workrelated skin and/or respiratory tract symptoms were selected for the examination. The examined group consisted of 13 women and 8 men. The mean age of the workers was 32 years (it ranged from 20 to 49 in females, and from 22 to 54 in males).

The job the workers performed was to spray polyurethane semi-rigid foam into moulds, using spray-guns. Before spraying, an antiadhesive agent was applied on the mould. According to material safety data sheets, workers were exposed to various chemicals: 4,4'-diphenylmethane diisocyanate (MDI), polyether polyol, formaldehyde, glycerol, propylene and ethylene oxide, tetramethyloimino-bispropylamine and N-[2-[2-(dimetyloamino)etoksy]etylo]$\mathrm{N}$-metylo-1,3-propanodiamine (aliphatic amines used as catalysts), stabilizer, antiadhesive agent (based on 1,3-butadiene in 10-20\% concentration, water and low-boiling petroleum fractions) and also metals and rubber. They worked based on a 3-shift system, in rooms with a high 
air temperature (about $28^{\circ} \mathrm{C}$ ). In spite of full availability of personal protective equipment, i.e. gloves and forearm protective sleeves, only some of the workers used it during work.

The workers were examined on the premises of the factory. They underwent clinical examination, patch testing, skin prick testing and spirometry. Additionally, measurement of specific IgE antibodies to MDI in serum was carried out. Patch tests were performed with 20 substances (Table 1) including chemicals from the occupational environment and a few others known as frequent contact allergens, such as isocyanate series, selected rubber additives and metals (Chemotechnique Diagnostics ${ }^{\circledR}$, Vellinge, Sweden). Also, a patch test with an antiadhesive agent "as is" was carried out in workers and in the control group of 20 individuals (healthy volunteers, 10 males, aged from 24 to 53, 10 females, aged from 22 to 55 , non-exposed to the antiadhesive agent nor other irritants in occupational setting). IQ Ultra ${ }^{\circledR}$ chambers (Chemotechnique Diagnostics ${ }^{\circledR}$ ) were used and applied on the upper part of the back. The readings were made on D2 and D4, according to the recommendations of the International Contact Dermatitis Research Group [22].

Skin prick tests with common aeroallergens, including house dust mites, pollens, fungi (Allergopharma, Germany; Stallergenes, France) and, additionally, a prickto-prick test with the antiadhesive agent in $0.01 \%, 0.5 \%$ and $1 \%$ water dilutions were also performed. Spirometry

Table 1. Patch test results in 21 examined workers reporting skin and/or respiratory symptoms, employed in a polyurethane equipment factory

\begin{tabular}{lccc}
\hline \multicolumn{1}{c}{ Allergen } & Females & Males & Total \\
& $(\mathrm{N}=14)$ & $(\mathrm{N}=7)$ & $(\mathrm{N}=21)$ \\
\hline Potassium dichromate 0.5 pet. & 1 & 0 & 1 \\
4-Phenylenediamine (PPD) 1.0 pet. & 6 & 1 & 7 \\
Thiuram mix 1.0 pet. & 0 & 0 & 0 \\
Cobalt(II) chloride hexahydrate 1.0 pet. & 2 & 1 & 3 \\
Nickel(II) sulfate hexahydrate 5.0 pet. & 2 & 0 & 2 \\
N-Isopropyl-N-phenyl-4-phenylenediamine (IPPD) 0.1 pet. & 1 & 0 & 1 \\
Mercapto mix 2.0 pet. & 1 & 0 & 1 \\
Formaldehyde 1.0 aq. & 0 & 0 & 0 \\
Fragrance mix I 8.0 pet. & 0 & 0 & 0 \\
Quaternium-15 1.0 pet. & 0 & 1 & 1 \\
Fragrance mix II 14.0 pet. & 0 & 0 & 0 \\
Euxyl K 400 1.5 pet. & 0 & 0 & 0 \\
Toluene-2,4-diisocyanate (TDI) 2.0 pet. & 0 & 0 & 0 \\
Diphenylmethane-4,4'-diisocyanate (MDI) 0.5 pet. & 0 & 0 & 0 \\
4,4'-Diaminodiphenylmethane (MDA) 0.5 pet. & 6 & 1 & 7 \\
Isophoronediisocyanate (IPDI) 1.0 pet. & 0 & 0 & 0 \\
Isophoronediamine (IPD) 0.1 pet. & 0 & 0 & 0 \\
1,6-Hexamethylenediisocyanate (HDI) 0.1 pet. & 0 & 0 & 0 \\
1,4-Butanediol diglycidylether 0.25 pet. & 0 & 0 & 5 IR \\
Antiadhesive agent (as is) & & 0 & \\
\hline
\end{tabular}


was carried out with the use of Spirometer Micro Lab ML 350 (Micro Medical Ltd, England) according to the criteria of the American Thoracic Society [23].

Specific MDI IgE ( $\operatorname{SgE}$ ) values were measured in sera by the ImmunoCAP 100 System (Phadia, Uppsala, Sweden) according to the manufacturer's recommendations.

\section{RESULTS}

From among 21 examined employees, 17 individuals (11 females, 6 males) suffered from work-related skin symptoms. They reported itchy, stinging and/or burning skin lesions, localized on the exposed, bare skin areas. At the beginning, usually the forearm skin, and then also the dorsal parts of the hands, face and neck were affected. The symptoms were appearing after from 3 days to 6 months since the first occupational exposure. In 1 person, the skin lesions appeared after $24 \mathrm{~h}$ on the face as a result of accidental indirect contact with the antiadhesive agent. Most of the examined patients had undergone dermatological treatment for skin lesions, 5 had been on sick leave and 4 had been moved to other duties because of the skin disease. According to the interview, skin and respiratory symptoms were related to the exposure to the antiadhesive agent, despite that none of its components was classified as a hazardous chemical according to the relevant safety data sheet. Dermatological examination revealed eczematous skin lesions localized in the area of hands and/or forearms in 10 workers ( 8 females and 2 males). In 2 persons, only acne lesions were found.

Eleven females and 4 males, in addition to skin disorders, reported moderate respiratory and ocular symptoms such as rhinorrhea/rhinitis, cough, redness of the conjunctiva and lachrymation. Four workers suffered only from respiratory symptoms without skin involvement.

Twenty individuals did not report any chronic diseases, one woman suffered from hypertension and was undergoing monotherapy with a diuretic. $47.6 \%$ (46.1\% of women, $50 \%$ of men) were smokers.

Table 1 shows the results of patch tests. Positive patch test reactions to occupational allergens and clinical diagnosis for particular individuals are shown in Table 2.

At least one positive patch test reaction was found in 10 individuals ( 8 females, 2 males). The most frequent allergens

Table 2. Results of patch tests and final diagnosis in individuals reporting work-related skin symptoms

\begin{tabular}{lrrlll}
\hline $\begin{array}{c}\text { Patient } \\
\text { number }\end{array}$ & Sex & Age & $\begin{array}{c}\text { Positive patch test reactions } \\
\text { at D2 or D4 }\end{array}$ & $\begin{array}{c}\text { Reaction to } \\
\text { antiadhesive agent }\end{array}$ & \multicolumn{1}{c}{$\begin{array}{c}\text { Diagnosis of occupational } \\
\text { disease }\end{array}$} \\
\hline 1 & female & 28 & MDA, PPD & IR & ACD, ICD \\
2 & female & 33 & MDA, PPD & - & ACD \\
3 & female & 35 & MDA, PPD & IR & ACD, ICD \\
4 & female & 27 & MDA, PPD & - & ACD \\
5 & female & 26 & Cr, MDA, PPD, IPPD, & IR & ACD, ICD \\
& & & Mercapto mix & & ACD \\
6 & female & 38 & MDA & - & ICD (current symptoms) \\
7 & female & 31 & PPD, Co & IR & ICD (current symptoms) \\
8 & female & 20 & Ni, Co & IR & ICD (symptoms in the past) \\
9 & female & 49 & - & - & ICD (current symptoms) \\
10 & female & 44 & - & - & ICD (symptoms in the past) \\
11 & female & 23 & - & - & ACD \\
12 & male & 22 & MDA, PPD & - & \\
\hline
\end{tabular}


Table 2. Results of patch tests and final diagnosis in individuals reporting work-related skin symptoms - cont.

\begin{tabular}{llllll}
\hline $\begin{array}{c}\text { Patient } \\
\text { number }\end{array}$ & Sex & Age & $\begin{array}{c}\text { Positive patch test reactions } \\
\text { at D2 or D4 }\end{array}$ & $\begin{array}{c}\text { Reaction to } \\
\text { antiadhesive agent }\end{array}$ & \multicolumn{1}{c}{$\begin{array}{c}\text { Diagnosis of occupational } \\
\text { disease }\end{array}$} \\
\hline 13 & male & 54 & Co, Quaternium-15 & - & ICD (current symptoms) \\
14 & male & 32 & - & - & ICD (symptoms in the past) \\
15 & male & 28 & - & - & ICD (symptoms in the past) \\
16 & male & 34 & - & - & ICD (symptoms in the past) \\
17 & male & 26 & - & - & ICD (current symptoms) \\
\hline
\end{tabular}

MDA - 4,4'-diaminodiphenylmethane; PPD - 4-phenylenediamine; $\mathrm{Cr}$ - potassium dichromate; IPPD - N-isopropyl-N-phenyl-4-phenylenediamine; $\mathrm{Co}$ - cobalt(II) chloride hexahydrate; $\mathrm{Ni}$ - nickel(II) sulfate hexahydrate; $\mathrm{ACD}$ - allergic contact dermatitis; ICD - irritant contact dermatitis.

were MDA and PPD (7 persons had positive test results to MDA and 7 to PPD). Six workers reacted simultaneously to PPD and MDA. No positive reactions were found to the remaining substances of isocyanate series, including MDI. Reactions to the antiadhesive agent were found to be irritant because of their clinical appearance and positive reactions in the control group (in 55\% of the volunteers). Skin prick tests with common aeroallergens were positive in 9 workers ( 5 females, 4 males). No immediate reactions were found to the antiadhesive agent.

In none of the subjects, any abnormalities in spirometry were found. $\mathrm{FEV}_{1}$ ranged from 88 to $115 \%, \mathrm{FEV}_{1} / \mathrm{VC}$ from 0.675 to 0.909 . MDI sIgE were not detected in sera (level < $35 \mathrm{kU} / \mathrm{l})$.

The final diagnosis of occupational ACD was established in 7 workers ( 6 females, 1 male), in 3 cases it coexisted with ICD. The remaining workers showing work-related dermal symptoms were diagnosed with occupational ICD.

\section{DISCUSSION}

Our investigations in the vehicle equipment factory revealed work-related contact dermatitis in 12 workers exposed to polyurethane foam containing MDI. Seven of them developed contact allergy to MDA and were diagnosed with occupational ACD. We observed also irritant skin reactions to the antiadhesive agent, in 3 cases coexisting with occupational ACD.
According to the analysis of safety data sheets, workers were exposed to MDI, but in patch testing, no positive reactions were found to this compound. However, 7 individuals reacted to MDA, despite of lack of confirmed presence of this chemical in occupational setting. In other studies, sensitization to MDA, was frequently found together with contact allergy to MDI and MDA was considered as an indicator of MDI contact sensitization [2-4,19,24,25]. Simultaneous reactions to MDI and MDA were attributed to their cross-reactivity related to the similar structure [26], although according to some authors, these two chemicals could have been both primary sensitizers [3]. In some reports, as in our study, individuals exposed to MDI did not react to this compound in patch testing, whereas positive reactions were observed to MDA, regardless of the presence or absence of MDA in occupational setting [2,3]. Such results had been explained by the fact that MDA could be formed from MDI by hydrolysis, i.e., a reaction with water on, or in, moist skin, especially in warm working conditions provoking sweating, as was the case in the examined workplace $[2,3,13,19,27]$. Another hypothesis suggests that concomitant reactions to 4,4'-MDI and 4,4'-MDA may be elucidated by the pathway of reactions of MDI, leading to ureas, oligoureas and MDI conjugates with skin constituents, which can be hydrolyzed into amines, including MDA [25].

Similar results of patch testing in subjects exposed to MDI were obtained by other authors. Goossens et al. report- 
ed 22 cases of occupation-related ACD from isocyanates and/or polyurethanes. Ten of the patients had a positive patch test to MDA along with a positive reaction to isocyanates (MDI in 5 cases), and 9 had a positive test reaction only to MDA [2]. Estlander et al. found a positive patch test reaction to MDA in a foreman who had not been previously exposed to this compound [13]. Tait and Delaney reported ACD in a maintenance fitter exposed to MDI. Patch tests with MDI were negative, but the reaction to MDA, regarded as an isocyanate metabolite, was positive [27]. Also Frick et al., in a company manufacturing boards coated with MDI-based lacquer, observed patch test reactions to MDA in 5 workers, but only 2 of them reacted also to MDI [3]. Aalto-Korte et al. diagnosed occupational sensitization related to MDI products in 17 cases, however only 8 reacted positively to MDI, and in 9 cases, similarly to our study, the diagnosis of occupational contact allergy was based on positive MDA reactions [4].

Another possible explanation to the absence of the expected positive reactions to MDI in our investigated group and in other studies may be the instability of commercially available 4,4'-MDI test substances. Frick et al. found poor correlation between the specified and true concentrations of 4,4'-MDI in petrolatum patch test preparations from 8 European and 4 American dermatology departments, which were found to contain no more than $12 \%$ of the concentrations specified in the label. The use of these preparations might have led to possible falsenegative reactions [28]. In the Finnish Institute of Occupational Medicine, an in-house test substance, containing 4,4'-MDI, MDI triisocyanate and 2,4'-MDI proved to be superior to commercial preparations of MDI [4]. Also Frick-Engfeldt et al. confirmed experimentally that patch tests with MDI products, and particularly polymeric MDI (PMDI) preparations, were superior to monomeric 4,4'-MDI in detecting contact allergy in patients exposed to MDI, because of their higher stability and homogeneity [25,29]. There were also suggestions that MDI preparations were stable only when they were kept frozen, and not routinely stored in a refrigerator [29]. Taking into account these considerations, it would be reasonable not to exclude that we obtained false-negative results because of the instability of test substance preparations and the insufficient content of MDI in the patch testing used in our investigation.

It is also noteworthy that in several previously reported cases of ACD to isocyanates, positive reactions appeared only on D7 [3,21,25]. It was suggested that isocyanates belong to the substances showing late-appearing reactions in patch testing. For this reason, the ordinary reading on D2/D4 is sometimes insufficient and readings on both D2/4 and D7 and even D10 are recommended [3,25]. In our investigation, the readings were made only on D2 and D4. Regarding positive patch test reactions caused by MDA, it should be noted that they are relatively often seen (even in 2-4\% of the patients tested), but their relevance is not always clear [28]. MDA may be used as a hardener of epoxy resins, an antioxidant of rubber products and in the production of synthetic textile fibers [13]. Also, various finished products may be a source of non-occupational exposure to MDA [22,30-32]. However, in workers composing our group, detailed medical and occupational history showed that another source of sensitization to MDA, apart from that of the present workplace, was rather unlikely. MDA, as a 4,4'-substituted molecule, belongs to the para-group chemicals and may cross-react with other para-compounds [30]. In our study, 6 persons reacted positively at the same time to MDA and PPD. One of them had a positive test reaction also to N-Isopropyl-Nphenyl-4-phenylenediamine (IPPD), another member of the para-group. Simultaneous reactions to MDA and PPD were obtained also by other authors $[4,22,30]$. However, in our group, almost all workers (6 among 7) sensitized to MDA reacted to PPD, while in other studies, only one third of the examined subjects showed concomitant reactions to MDA and PPD [4,22,30]. 
Outbreaks of work-related skin lesions due to isocyanates among workers of other companies were noted. Frick et al. reported an outbreak of ACD in a company producing flooring laminate boards, after the introduction of a water-repellent lacquer based on MDI. Five workers, employed as machine operators where lacquer was sprayed onto the boards, developed eczematous lesions of the forearms, hands or arms. Patch testing showed positive reactions to MDA in 4, to MDI in 1, to HDMI in 1 and to lacquer in 3 of them [3]. White et al. demonstrated ACD and ICD due to DMDI in uncured resin in a factory of car badges [17]. Emmet et al. reported skin rashes on exposed skin areas in 8 employees of polyurethane molding plant, with positive patch test reactions to DMDI and MDA in two of them [33]. Frick et al. reported an outbreak of eczema in 17 workers exposed to glue based on DMDI, at a factory manufacturing medical equipment. Contact allergy to DMDI, other isocyanates and/or MDA was demonstrated in 13 individuals [19].

Isolated cases of allergic contact dermatitis in workers exposed to MDI were also previously reported, in different occupational settings. Hannu et al. demonstrated a case of ACD due to MDI and MDA from accidental occupational exposure in a female worker employed in a manufacturing plant of electronic components [15]. Schröder reported a case of ACD to MDI (present in polyurethane adhesive), TDI, MDA and epoxy resin in a female employed in a plant manufacturing grinding tools [14]. Estlander et al. diagnosed occupational contact dermatitis in 3 workers exposed to MDI present, respectively, in a hardener of core binder, a hardener of adhesives and a laboratory mixture of diisocyanates [13]. Lidén reported a case of ACD of the forearms in a molder exposed to MDI-containing product in a hospital [12]. As mentioned above, Tait and Delaney reported a case of a maintenance fitter who developed ACD after cleaning filters contaminated with aptane isocyanate based on MDI [27]. Our case came from the automobile industry. According to Aalto-Korte et al., who analyzed 54 cases of ACD due to monomeric isocyanates, motor vehicle industry was among the most significant occupational fields for isocyanate contact allergy. They identified many sources of allergy to MDI, e.g., PU foam used in the production of car insulation material, pistol foam containing MDI and uncured PU insulating material, which is similar to exposure in our factory [4]. In the study by Goossens et al. quoted earlier, among persons exposed to MDI who developed contact allergy, there was a worker engaged in the manufacturing of floor carpets for cars [2].

Besides allergic reactions, also irritant skin lesions were observed in our study. In workers reporting work-related eczematous skin symptoms (particularly of the hands and forearms), who had negative patch test results to MDA, and in 3 subjects with contact allergy, ICD was diagnosed, due to the antiadhesive agent. The diagnosis was based on medical history (eczematous skin lesions in the past) or clinical examination (current eczematous skin lesions). It is also likely that irritant reactions may have preceded the development of allergic contact dermatitis in individuals with contact sensitization to MDA. The rapid onset of skin symptoms, i.e. within a few days of exposure to PU foam, indicates the irritant nature of the lesions. It should be emphasized that in patch testing in the examined and control group, we obtained irritant reactions to the antiadhesive agent despite the fact that its components were not classified as irritant chemicals.

Some studies suggest that not only inhalatory exposure, but also skin contact with isocyanates may contribute to the development of asthma [5]. Nevertheless, in our study, although some workers complained of respiratory tract symptoms, the results of conducted examinations, including skin prick tests, spirometry and MDI sIgE measurement, did not point to occupational and allergic origin of reported disorders.

Most authors emphasized that poor hygienic conditions and lack of efficient skin protection were usually 
responsible for contact allergies amongst workers exposed to isocyanates $[1,3]$. In our group, it was probably insufficient skin protection that contributed most profoundly to the outbreak of skin problems. Due to the high air temperature in the factory premises, employees wore T-shirts with short sleeves and only some of them occasionally used forearm protective clothes. It is known that good protection of the hands and also forearms is essential when PU chemicals are handled [13]. Gloves and protective clothing remain a primary means of preventing skin exposure in the workplace, in addition to engineering and work practice controls. In case of exposure to isocyanates, nitrile gloves are considered preferable to latex [5].

In conclusion, in workers manufacturing various products from polyurethanes, attention should be paid to the risk of developing allergic and irritant contact dermatitis. Despite the fact that isocyanates represent substances hazardous first of all to the respiratory tract, in our investigated group, exposure to polyurethane foam led to the development of skin disorders, while the respiratory tract was not significantly involved. Avoiding skin contamination from isocyanates and other substances used during the manufacturing process is essential to minimize the risk of development of allergic and irritant reactions. Workers from our group were advised to use gloves and protective clothes, covering forearms and arms during foam spraying.

\section{REFERENCES}

1. Estlander T, Kanerva L, Jolanki R. Polyurethane resins. In: Kanerva L, Elsner P, Wahlberg JE, Maibach HI, editors. Handbook of occupational dermatology. New York: SpringerVerlag; 2000. p. 597-601, http://dx.doi.org/10.1007/978-3-66207677-4_75.

2. Goossens A, Detienne T, Bruze M. Occupational allergic contact dermatitis caused by isocyanates. Contact Dermatitis. 2002;47(5):304-8, http://dx.doi.org/10.1034/j.1600-0536. 2002.470509.x.
3. Frick M, Isaksson M, Björkner B, Hindsén M, Pontén A, Bruze M. Occupational allergic contact dermatitis in a company manufacturing boards coated with isocyanate lacquer. Contact Dermatitis. 2003;48(5):255-60, http://dx.doi. org/10.1034/j.1600-0536.2003.00107.x.

4. Aalto-Korte K, Suuronen K, Kuuliala O, Henriks-Eckerman M-L, Jolanki R. Occupational contact allergy to monomeric isocyanates. Contact Dermatitis. 2012;67(2):78-88, http://dx.doi.org/10.1111/j.1600-0536.2011.02049.x.

5.75 years polyurethanes [Internet]. Automotive applications [cited 2013 Jan 3]. Available from: http://www.polyurethanes.org/index.php?page =automotive.

6. Bello D, Herrick CA, Smith TJ, Woskie SR, Streicher RP, Cullen MR, et al. Skin exposure to isocyanates: reasons for concern. Environ Health Perspect. 2007;115(3):328-35, http://dx.doi.org/10.1289/ehp.9557.

7. Świerczyńska-Machura D, Pałczyński C. [Selected pathogenetic and clinical aspects of asthma from occupational exposure to diisocyanates]. Med Pr. 2012;63(1):97-103. Polish.

8. Kanerva L, Grenquist-Nordén B, Piirilä P. Occupational IgE-mediated contact urticaria from diphenylmethane-4,4'diisocyanate (MDI). Contact Dermatitis. 1999;41(1):50, http://dx.doi.org/10.1111/j.1600-0536.1999.tb06215.x.

9. Stingeni L, Bellini V, Lisi P. Occupational airborne contact urticaria and asthma: simultaneous immediate and delayed allergy to diphenylmethane-4,4'-diisocyanate. Contact Dermatitis. 2008;58(2):112-3, http://dx.doi.org/10.1111/j.16000536.2007.01180.x.

10. Valks R, Conde-Salazar L, López Barrantes O. Occupational allergic contact urticaria and asthma from diphenylmethane4,4'-diisocyanate. Contact Dermatitis. 2003;49(3):166-7, http://dx.doi.org/10.1111/j.0105-1873.2003.0185j.x.

11. A summary of health hazard evaluations: issues related to occupational exposure to isocyanates, 1989 to 2002. Department of Health and Human Services, Centers for Disease Control and Prevention, National Institute for Occupational Safety and Health; January 2004 [cited 2012 Dec 20]. Available from: http://www.cdc.gov/niosh/docs/2004-116/pdfs/2004-116.pdf. 
12. Lidén C. Allergic contact dermatitis from 4,4'diisocyanatodiphenylmethane (MDI) in a molder. Contact Dermatitis. 1980;6(4):301-2.

13. Estlander T, Keskinen H, Jolanki R, Kanerva L. Occupational dermatitis from exposure to polyurethane chemicals. Contact Dermatitis. 1992;27(3):161-5.

14. Schröder C, Uter W, Schwanitz HJ. Occupational allergic contact dermatitis, partly airborne, due to isocyanates and epoxy resin. Contact Dermatitis. 1999;41(2):117-8.

15. Hannu T, Estlander T, Jolanki R. Allergic contact dermatitis due to MDI and MDA from accidental occupational exposure. Contact Dermatitis. 2005;52(2):108-9, http://dx.doi. org/10.1111/j.0105-1873.2005.00498b.x.

16. Aalto-Korte K, Pesonen M, Kuuliala O, Alanko K, Jolanki R. Contact allergy to aliphatic polyisocyanates based on hexamethylene-1,6-diisocyanate (HDI). Contact Dermatitis. 2010;63(6):357-63, http://dx.doi.org/10.1111/j.1600-0536. 2010.01786.x.

17. White IR, Stewart JR, Rycroft RJ. Allergic contact dermatitis from an organic di-isocyanate. Contact Dermatitis. 1983;9(4):300-3, http://dx.doi.org/10.1111/j.1600-0536.1983. tb04395.x.

18. Thompson T, Belsito DV. Allergic contact dermatitis from a diisocyanate in wool processing. Contact Dermatitis. 1997;37(5):239, http://dx.doi.org/10.1111/j.1600-0536.1997. tb02446.x.

19. Frick M, Björkner B, Hamnerius N, Zimerson E. Allergic contact dermatitis from dicyclohexylmethane-4,4'-diisocyanate. Contact Dermatitis. 2003;48(6):305-9, http://dx.doi. org/10.1034/j.1600-0536.2003.00123.x.

20. Kerre S. Allergic contact dermatitis to DMDI in an office application. Contact Dermatitis. 2008;58(5):313-4, http:// dx.doi.org/10.1111/j.1600-0536.2007.01290.x.

21. Donovan JCH, Kudla I, DeKoven JG. Rapid development of allergic contact dermatitis from dicyclohexylmethane4,4'-diisocyanate. Dermatitis. 2009;20(4):214-7.

22. American Thoracic Society. Standardization of spirometry 1994 update. Am J Respir Crit Care Med. 1995;152(3):1107-36.
23. Wahlberg JE. Patch testing. In: Rycroft RJG, Menné T, Frosch PJ, Lepoittevin JP, editors. Textbook of contact dermatitis. 3rd ed. Berlin: Springer; 2001. p. 439-68.

24. Lippo J, Lammintausta K. Contact sensitization to 4,4'-diaminophenylmethane and to isocyanates among general dermatology patients. Contact Dermatitis. 2008;59(2):109-14.

25. Frick-Engfeldt M, Isaksson M, Zimerson E, Bruze M. How to optimize patch testing with diphenylmethane diisocyanate. Contact Dermatitis. 2007;57(3):138-51, http://dx.doi. org/10.1111/j.1600-0536.2007.01197.x.

26. Fregert S. Allergic contact reaction to diphenyl-4,4'-diisocyanate. Contact Dermatitis Newsletter. 1967;2:17.

27. Tait CP, Delaney TA. Reactions causing reactions: Allergic contact dermatitis to an isocyanate metabolite but not to the parent compound. Australasian J Dermatol.1999;40(2):116-7, http://dx.doi.org/10.1046/j.1440-0960. 1999.00335.x.

28. Frick M, Zimerson E, Karlsson D, Marand Å, Skarping G, Isaksson $\mathrm{M}$, et al. Poor correlation between stated and found concentrations of diphenylmethane-4,4'-diisocyanate (4.4'-MDI) in petrolatum patch-test preparations. Contact Dermatitis. 2004;51(2):73-8, http://dx.doi.org/10.1111/ j.0105-1873.2004.00404.x.

29. Frick-Engfeldt M, Zimerson E, Karlsson D, Skarping G, Isaksson $\mathrm{M}$, Bruze $\mathrm{M}$. Is it possible to improve the patchtest diagnostics for isocyanates? A stability study of petrolatum preparations of diphenylmethane-4,4'-diisocyanate and polymeric diphenylmethane diisocyanate. Contact Dermatitis. 2007;56(1):27-34, http://dx.doi.org/10.1111/j.16000536.2007.01007.x.

30. Belloni Fortina A, Piaserico S, Larese F, Recchia GP, Corradin MT, Gennaro F, et al. Diaminodiphenylmethane (DDM): frequency of sensitization, clinical relevance and concomitant positive reactions. Contact Dermatitis. 2001;44(5):283-8.

31. Alomar A. Contact dermatitis from a fashion watch. Contact Dermatitis. 1986;15(1):44-5, http://dx.doi.org/10.1111/ j.1600-0536.1986.tb01267.x. 
32. Grimalt R, Vilaplana J, Romaguera C. Three cases of allergic contact dermatitis to 4,4'-diaminodiphenylmethane. Contact Dermatitis. 2009;60(6):346-7, http://dx.doi. org/10.1111/j.1600-0536.2009.01554.x.
33. Emmett EA. Allergic contact dermatitis in polyurethane plastic moulders. J Occup Med. 1976;18(12):802-4, http:// dx.doi.org/10.1097/00043764-197612000-00006.

This work is available in Open Access model and licensed under a Creative Commons Attribution-NonCommercial 3.0 Poland License - http://creativecommons.org/ licenses/by-nc/3.0/pl/deed.en. 